\title{
Medial Rectus Muscle Advancement in Consecutive Exotropia*
}

\author{
Stefano Pensiero", Maurizio Madonia, Fulvio Parentin, Dario Catalano \\ Department of Ophthalmology, Institute for Maternal and Child Health-IRCCS "Burlo Garofolo", Trieste, Italy. \\ Email: " pensiero@burlo.trieste.it
}

Received March $5^{\text {th }}, 2013$; revised April $2^{\text {nd }}, 2013$; accepted May $2^{\text {nd }}, 2013$

Copyright (C) 2013 Stefano Pensiero et al. This is an open access article distributed under the Creative Commons Attribution License, which permits unrestricted use, distribution, and reproduction in any medium, provided the original work is properly cited.

\begin{abstract}
Purpose: Consecutive exotropia is a frequent consequence of surgery for convergent strabismus that may develop at differing rates postoperatively. Several surgical options on horizontal recti have been proposed, but none report a clearly standardized amount of surgery. The present study provides further results of the medial rectus muscle advancement. Methods: Twenty-eight patients, age ranged from 6 - 55 years, who had undergone unilateral or bilateral medial rectus advancement to the physiological insertion, with or without contemporary unilateral lateral rectus muscle recession, were included in the study. Factors leading to the onset of consecutive exotropia were analyzed. Results: After 2 3 years, the overall mean angle reduction was 21.3 prismatic diopters (PD) for distance and 22.8 PD for near, with an effectiveness on near vision lower than expected. Only in the 7 cases with a preoperatively larger exotropia at near (of at least 10 PD), the reduction was 17.0 PD for distance and 24.6 PD for near. In unilateral medial rectus muscle advancement, the mean reduction was 14.3 PD for distance and 16.3 PD for near; in bilateral advancement it was 25.8 PD and 25.2 PD respectively. Conclusion: Medial rectus advancement is preferable to other options, especially in cases with convergence deficit, if no excess of divergence or limitation of bulb rotation is present, for which a lateral rectus muscle recession is indicated. Unilateral and bilateral surgeries are useful for exotropia of about 15 PD and 25 PD respectively. The effectiveness depends weakly or not at all on the amount of the previously executed recession.
\end{abstract}

Keywords: Consecutive Exotropia; Medial Rectus Advancement; Strabismus Surgery

\section{Introduction}

Divergent strabismus that develops after esotropia surgery is called consecutive exotropia and occurs in about one quarter of cases, either immediately after surgery or many years later [1]. Many factors causing the development of this surgical complication have been reported. They are amblyopia, limitations of bulb rotation, vertical deviation, A and V patterns, nystagmus, large medial rectus recessions, high hyperopia, multiple surgeries, and developmental delay [1-4].

The surgical approach to this type of strabismus includes several options that are differently used by various authors, but with no clear standard amount of surgery. In particular, the surgical dosage for medial rectus muscle (MRM) advancement is not provided in tables. Only Parks [5] developed tables to use for the surgical correc-

${ }^{*}$ Conflict of Interest and Source of Funding: No conflicts of interest are declared.

${ }^{\#}$ Corresponding author. tion of concomitant exodeviations that are often used also in consecutive exotropia. In this case, a 1-mm advancement in MRM was considered equivalent to a 1$\mathrm{mm}$ resection of the same muscle. However, the advancement of already recessed muscles should theoretically have a greater effect than resection, even if this has only been demonstrated for previous recessions larger than $8 \mathrm{~mm}$ from limbus [6].

All authors agree that the decision regarding the surgical procedure to be taken entails an evaluation of the type and amount of previous surgery and the presence of limitation of adduction (sometimes linked to the presence of scar traction) or convergence insufficiency. In fact, large recessions of the MRM (exceeding $5 \mathrm{~mm}$ ) can produce consecutive exotropia and limitation of adduction; large resections of the lateral rectus muscle (LRM) can cause a limitation of MRM function. Marcon [7] proposed performing intraoperative muscle stretch test before deciding on the amount of muscle advancement.

In principle, MRM advancement combined with LRM 
recession is indicated for patients with consecutive exotropia with limited adduction after bilateral MRM recession, or in cases that underwent unilateral MRM recession/LRM resection surgery. Bilateral LRM recession is indicated for patients with divergence excess or exotropia with normal MRM function, but it should be avoided in patients with limitation of adduction [8].

Most authors use unilateral surgery on a non-dominant or amblyopic eye, especially in cases with unilateral amblyopia. Donaldson et al. [8], for exotropia $<50$ prismatic dioptres (PD), followed Parks' tables and performed an advancement of MRM (to the original insertion, or behind it, sometimes with resection) together with a LRM recession, with a $71 \%$ success rate, both in cases of bilateral MRM recession and unilateral MRM recession/LRM resection as primary procedure for esotropia. Mohan et al. [6], using the same approach, referred of a success rate of $68 \%$. Chatzistefanou et al. [9] performed a unilateral reversal of the preceding surgery, especially in cases of unilateral two-muscle surgery for esotropia. Results were good for exodeviations in the range of 25 - $40 \mathrm{PD}$, with a slight undercorrection. These authors underlined the necessity to re-operate or at least explore the already-operated muscles. This was recommended in cases of abnormal ductions, where a slipped or excessively recessed MRM is suspected, or when a positive forced duction testing in adduction indicates a tight LRM or a contractured temporal conjunctiva. Other authors [4] prefer to perform a bilateral LRM recession for deviations up to $35 \mathrm{PD}$, associating an advancement of one or both MRM if exotropia is larger. The success rate with this approach was 70\%. Also Patel et al. [10] performed bilateral LRM recessions, achieving a successful alignment in $65 \%$ of cases. In $46 \%$ of cases with a deviation larger for distance than for near of at least 10 PD, the bilateral LRM recession clearly reduced this difference.

Finally, regarding the surgical dosage for MRM advancement, the efficacy of MRM advancement alone was tested by Ohtsuki et al. [11] and Biedner et al. [12]. All the patients of Ohtsuki et al. [11] underwent single or bilateral advancement of the MRM to the original insertion. The mean preoperative exodeviation was 27 PD at distance and 35 PD at near. Postoperatively, in cases receiving advancement of a single MRM, the mean amount of correction was $23 \mathrm{DP}$ at distance and $30 \mathrm{DP}$ at near. In cases receiving bilateral MRM advancement, it was 26 DP at distance and 40 DP at near.

Biedner et al. [12] suggested a unilateral MRM advancement up to the original insertion for deviations $\leq 25$ $\mathrm{PD}$, to $2 \mathrm{~mm}$ beyond the original insertion for deviations of 30 - 35 PD, and concomitant resection or additional muscle surgery for deviations $>35$ PD. Mohan et al. [6] prefer to perform a resection whenever possible (in his series it was possible $50 \%$ of cases), rather than an MRM advancement, because the advanced muscle may adhere to the sclera at the site of the previous insertion, producing a form of posterior fixation on the muscle that could reduce the effect of the advancement. On the contrary, Chatzistefanou et al. [9] believe that resecting a formerly recessed muscle may only increase the intraoperative challenge without substantial benefits.

The angle of consecutive exotropia does not depend on the extent of the MRM recession already made and, in our experience, the effectiveness of the muscle progress does not follow a linear $\mathrm{mm} / \mathrm{PD}$ law. Therefore in a group of patients with consecutive exotropia we reported the MRM to its original insertion to evaluate the efficacy of this procedure on distant and near deviations. The final evaluation was carried out after two years after surgery.

\section{Patients and Methods}

We retrospectively reviewed the records of 28 patients who had undergone surgery for consecutive exotropia and had been followed up for 2 to 3 years. In all cases, a unilateral or bilateral MRM advancement to the original insertion was performed by the same surgeon (SP), together with a unilateral $7 \mathrm{~mm}$ LRM recession in some cases. The study group consisted of 18 males and 10 females, with age ranging from 6 to 55 years at the time of the MRM advancement.

The clinical assessment of all patients (visual acuity, cycloplegic refraction and preoperative deviations for distance, $6 \mathrm{~m}$, and for near, $33 \mathrm{~cm}$ ) is shown in Table 1. Since we have chosen only cases with full written documentation about their previous oculomotor situation and surgery that they had already undergone, the amount of the initial convergent deviation, the age at the time of the first surgery and the number of operations performed before the MRM advancement are also reported in the table. Finally, Table 1 includes the type and amount (in $\mathrm{mm}$ ) of horizontal rectus muscle interventions that had already been performed and the years that elapsed between the first operation for esotropia and the last for consecutive exotropia.

The clinical history shows that some subjects had presented a vertical deviation or an alphabetic pattern that had been operated by uni- or bilateral recession of the muscle inferior oblique or unilateral superior rectus recession. Three patients (n. 6, n. 7, and n. 9) had an accommodative excess of convergence already at the time of the first operation. A psychomotor delay was evident only in patients n. 1 and n. 2 .

Surgery consisted of MRM advancements that were equivalent in length $(\mathrm{mm})$ to that of the recession that was performed at the time of surgery for esotropia, as indicated in the surgical records, in order to return the 
Table 1. Ophthalmic characteristics of all considered cases.

\begin{tabular}{|c|c|c|c|c|c|c|c|c|c|c|c|}
\hline \multirow[t]{2}{*}{$\begin{array}{c}\text { Patient } \\
\text { Nr. }\end{array}$} & \multirow[t]{2}{*}{ Sex } & \multirow[t]{2}{*}{$\begin{array}{c}\text { Original } \\
\text { Angle } \\
\text { (PD) }\end{array}$} & \multirow[t]{2}{*}{$\begin{array}{c}\text { Date of 1st } \\
\text { Surgery } \\
\text { (years) }\end{array}$} & \multirow[t]{2}{*}{$\begin{array}{c}\text { Nr. of } \\
\text { Surgery } \\
\text { performed }\end{array}$} & \multirow[t]{2}{*}{$\begin{array}{c}\text { Operated } \\
\text { Horizontal } \\
\text { Recti (mm) }\end{array}$} & \multirow[t]{2}{*}{$\begin{array}{c}\text { Years } \\
\text { after 1st } \\
\text { Operation }\end{array}$} & \multicolumn{2}{|c|}{$\begin{array}{l}\text { Visual Acuity } \\
\text { Cycloplegic } \\
\text { Refraction }\end{array}$} & \multirow[t]{2}{*}{$\begin{array}{l}\text { Angle (PD) } \\
\text { Distance } \\
\text { Near }\end{array}$} & \multirow[t]{2}{*}{ Operation } & \multirow[t]{2}{*}{$\begin{array}{l}\text { Resuts at } \\
2 \text { - } 3 \text { Years } \\
\text { (PD) }\end{array}$} \\
\hline & & & & & & & RE & LE & & & \\
\hline 1 & M & +70 & 2 & 2 & BMRC (6.0) BLRS (7.0) & 10 & $\begin{array}{l}20 / 20 \\
-2.25\end{array}$ & $\begin{array}{l}20 / 40 \\
-2.50\end{array}$ & -25 & $\begin{array}{l}\text { UMRA } \\
\text { ULRC }\end{array}$ & $\begin{array}{c}\text { ortho } \\
-10\end{array}$ \\
\hline 2 & M & +45 & 4 & 1 & BMRC (5.0) & 6 & $\begin{array}{l}20 / 20 \\
+0.50\end{array}$ & $\begin{array}{r}20 / 20 \\
+3.50\end{array}$ & $\begin{array}{l}-20 \\
-40\end{array}$ & UMRA & $\begin{array}{c}-4 \\
-14\end{array}$ \\
\hline 3 & $\mathrm{~F}$ & +50 & 1 & 1 & BMRC (5.0) & 11 & $\begin{array}{l}20 / 20 \\
-1.50\end{array}$ & $\begin{array}{l}20 / 50 \\
-1.50\end{array}$ & $\begin{array}{l}-12 \\
-25\end{array}$ & UMRA & $\begin{array}{l}\text { ortho } \\
+4\end{array}$ \\
\hline 4 & $\mathrm{~F}$ & +50 & 2 & 2 & BMRC (5.0) BLRS (7.0) & 12 & $\begin{array}{l}20 / 30 \\
+3.00\end{array}$ & $\begin{array}{r}20 / 30 \\
+2.00\end{array}$ & $\begin{array}{l}-16 \\
-30\end{array}$ & UMRA & $\begin{array}{l}\text { ortho } \\
-8\end{array}$ \\
\hline 5 & $\mathrm{~F}$ & +16 & 3 & 1 & UMRC (6.0) & 4 & $\begin{array}{l}20 / 25 \\
+2.00\end{array}$ & $\begin{array}{r}20 / 20 \\
+1.50\end{array}$ & $\begin{array}{l}-20 \\
-16\end{array}$ & UMRA & ortho \\
\hline 6 & $\mathrm{~F}$ & $+25 /+40$ & 4 & 2 & BMRC (5.0) & 3 & $\begin{array}{l}20 / 30 \\
+0.25\end{array}$ & $\begin{array}{r}20 / 30 \\
+1.50\end{array}$ & $\begin{array}{l}-40 \\
-20\end{array}$ & BMRA & $\begin{array}{l}-14 \\
\text { ortho }\end{array}$ \\
\hline 7 & $\mathrm{~F}$ & $+25 /+45$ & 4 & 1 & BMRC (5.0) & 2 & $\begin{array}{l}20 / 22 \\
-2.25\end{array}$ & $\begin{array}{l}20 / 30 \\
-2.00\end{array}$ & $\begin{array}{l}-30 \\
-20\end{array}$ & UMRA & $\begin{array}{l}-12 \\
-6\end{array}$ \\
\hline 8 & M & +30 & 4 & 2 & BMRC (5.0) & 6 & $\begin{array}{l}20 / 30 \\
+1.00\end{array}$ & $\begin{array}{l}20 / 25 \\
+1.00\end{array}$ & -16 & UMRA & $\begin{array}{l}-6 \\
-4\end{array}$ \\
\hline 9 & M & $+16 /+35$ & 6 & 3 & BMRC (6.0) & 7 & $\begin{array}{l}20 / 20 \\
+2.00\end{array}$ & $\begin{array}{r}20 / 20 \\
+2.25\end{array}$ & $\begin{array}{l}-35 \\
-14\end{array}$ & BMRA & $\begin{array}{l}-14 \\
\text { ortho }\end{array}$ \\
\hline 10 & M & +45 & 2 & 1 & BMRC (5.5) & 6 & $\begin{array}{l}20 / 30 \\
+0.50\end{array}$ & $\begin{array}{l}20 / 20 \\
+0.50\end{array}$ & $\begin{array}{l}-25 \\
-30\end{array}$ & BMRA & ortho \\
\hline 11 & M & +45 & 3 & 1 & BMRC (5.5) & 8 & $\begin{array}{l}20 / 20 \\
+3.00\end{array}$ & $\begin{array}{l}20 / 20 \\
+0.25\end{array}$ & $\begin{array}{l}-16 \\
-12\end{array}$ & UMRA & ortho \\
\hline 12 & M & +45 & 2 & 2 & BMRC (7.0) & 4 & $\begin{array}{l}20 / 40 \\
+4.00\end{array}$ & $\begin{array}{l}20 / 22 \\
+4.00\end{array}$ & $\begin{array}{l}-20 \\
-30\end{array}$ & $\begin{array}{l}\text { UMRA } \\
\text { ULRC }\end{array}$ & $\begin{array}{l}-6 \text {; } \\
\text { ortho }\end{array}$ \\
\hline 13 & $\mathrm{~F}$ & +50 & 2 & 1 & BMRC (6.0) & 9 & $\begin{array}{l}20 / 25 \\
+1.50\end{array}$ & $\begin{array}{r}20 / 20 \\
+1.75\end{array}$ & $\begin{array}{l}-16 \\
-20\end{array}$ & UMRA & ortho \\
\hline 14 & $\mathrm{~F}$ & +30 & 4 & 1 & BMRC (5.0) & 6 & $\begin{array}{l}20 / 20 \\
+1.25\end{array}$ & $\begin{array}{l}20 / 20 \\
+1.50\end{array}$ & $\begin{array}{l}-25 \\
-14\end{array}$ & UMRA & $\begin{array}{c}-14 \\
-4\end{array}$ \\
\hline 15 & M & +40 & 3 & 1 & BMRC (5.0) & 6 & $\begin{array}{l}20 / 30 \\
+4.25\end{array}$ & $\begin{array}{l}20 / 20 \\
+4.00\end{array}$ & $\begin{array}{l}-10 \\
-14\end{array}$ & UMRA & $\begin{array}{c}+4 \\
\text { ortho }\end{array}$ \\
\hline 16 & M & +45 & 6 & 2 & BMRC (6.0) ULRS (7.0) & 49 & $\begin{array}{c}20 / 200 \\
+2.25\end{array}$ & $\begin{array}{l}20 / 20 \\
+1.25\end{array}$ & -70 & $\begin{array}{l}\text { BMRA } \\
\text { ULRC }\end{array}$ & $\begin{array}{l}-4 \\
-8\end{array}$ \\
\hline 17 & M & +30 & 5 & 3 & BMRC (6.0) & 22 & $\begin{array}{l}20 / 20 \\
-2.75\end{array}$ & $\begin{array}{l}20 / 20 \\
-4.25\end{array}$ & $\begin{array}{l}-14 \\
-16\end{array}$ & UMRA & ortho \\
\hline 18 & $\mathrm{~F}$ & +45 & 5 & 2 & UMRC (6.0) ULRS (7.0) & 26 & $\begin{array}{c}20 / 100 \\
+3.25\end{array}$ & $\begin{array}{r}20 / 20 \\
+0.50\end{array}$ & $\begin{array}{l}-25 \\
-35\end{array}$ & $\begin{array}{l}\text { UMRA } \\
\text { ULRC }\end{array}$ & $\begin{array}{l}\text { ortho } \\
-8\end{array}$ \\
\hline 19 & M & +60 & 3 & 2 & BMRC (6.0) BLRS (5.0) & 36 & $\begin{array}{l}20 / 25 \\
+0.25\end{array}$ & $\begin{array}{l}20 / 22 \\
+0.25\end{array}$ & $\begin{array}{l}-50 \\
-55\end{array}$ & $\begin{array}{l}\text { BMRA } \\
\text { ULRR }\end{array}$ & -6 \\
\hline 20 & M & +35 & 9 & 2 & BMRC (6.0) & 29 & $\begin{array}{l}20 / 20 \\
+0.50\end{array}$ & $\begin{array}{l}20 / 25 \\
+1.25\end{array}$ & -60 & $\begin{array}{l}\text { BMRA } \\
\text { ULRC }\end{array}$ & $\begin{array}{c}-14 \\
-8\end{array}$ \\
\hline 21 & M & +45 & 3 & 2 & BMRC (5.0) BLRS (7.0) & 15 & $\begin{array}{l}20 / 20 \\
+1.50\end{array}$ & $\begin{array}{l}20 / 20 \\
+1.75\end{array}$ & $\begin{array}{l}-30 \\
-40\end{array}$ & $\begin{array}{l}\text { UMRA } \\
\text { ULRR }\end{array}$ & $\begin{array}{l}\text { ortho } \\
-10\end{array}$ \\
\hline 22 & M & +30 & 2 & 1 & BMRC (5.0) & 8 & $\begin{array}{l}20 / 20 \\
+3.00\end{array}$ & $\begin{array}{r}20 / 20 \\
+3.50\end{array}$ & $\begin{array}{l}-16 \\
-18\end{array}$ & UMRA & ortho \\
\hline 23 & M & +25 & 3 & 2 & BMRC (5.0) & 6 & $\begin{array}{l}20 / 20 \\
+1.50\end{array}$ & $\begin{array}{r}20 / 20 \\
+1.50\end{array}$ & $\begin{array}{l}-10 \\
-20\end{array}$ & UMRA & $\begin{array}{c}-4 \\
-12\end{array}$ \\
\hline 24 & M & +30 & 4 & 2 & BMRC (5.0) & 6 & $\begin{array}{l}20 / 20 \\
+0.75\end{array}$ & $\begin{array}{r}20 / 20 \\
+0.75\end{array}$ & -16 & UMRA & -6 \\
\hline 25 & M & +35 & 1 & 1 & BMRC (5.0) & 8 & $\begin{array}{l}20 / 20 \\
-0.25\end{array}$ & $\begin{array}{l}20 / 20 \\
-0.50\end{array}$ & -30 & BMRA & +4 \\
\hline 26 & $\mathrm{~F}$ & +40 & 2 & 2 & BMRC (5.5) & 29 & $\begin{array}{l}20 / 25 \\
+3.25\end{array}$ & $\begin{array}{r}20 / 20 \\
+0.50\end{array}$ & -25 & UMRA & -8 \\
\hline 27 & $\mathrm{~F}$ & +30 & 5 & 1 & BMRC (5.0) & 11 & $\begin{array}{l}20 / 20 \\
-1.25\end{array}$ & $\begin{array}{l}20 / 25 \\
-1.50\end{array}$ & $\begin{array}{l}-25 \\
-30\end{array}$ & BMRA & +6 \\
\hline 28 & M & +35 & 2 & 1 & BMRC (5.0) & 10 & $\begin{array}{l}20 / 20 \\
-0.25\end{array}$ & $\begin{array}{r}20 / 20 \\
+2.25\end{array}$ & -16 & UMRA & ortho \\
\hline
\end{tabular}

BMRC: bilateral medial rectus muscle recession; UMRC: unilateral medial rectus muscle recession; BLRS: bilateral lateral rectus muscle resection; ULRS: unilateral lateral rectus muscle resection; BMRA: bilateral medial rectus muscle advancement; UMRA: unilateral medial rectus muscle advancement; ULRC: unilateral lateral rectus muscle recession; PD: prismatic diopters; RE: right eye; LE: left eye; Ortho: orthotropia; Cycloplegic refraction: spherical equivalent, cyclopentolate. 
MRM to its physiological insertion. In fact normally the already operated MRM advancement is considered as if it were a shift from the physiological insertion: a certain number of $\mathrm{mm}$ corresponds to a certain angle of reduction of strabismus. But this is not what happens: consecutive exotropia is the jatrogenic result of a dislocation of the muscle by the insertion. Therefore we wanted to test the effect of repositioning the insertion of the muscle to the physiologic scleral position, that could be at least partially independent from the angle to correct, also because we know that the angle in many cases would further increase with age if no surgery is performed.

Through a delicate dissection of the tissues the muscle insertion was detected, and after a control of the absence of slippage of the muscle or the presence of pseudotendons (that would increase the size of the recession), the tendon-muscle insertion was advanced taking care to preserve the capsule below the muscle and after a cleaning of tendon residues on the insertion, to prevent adhesions of the muscle to the sclera. A unilateral MRM advancement alone was utilized for desired angle reduction up to $25 \mathrm{PD}$, as recommended by Biedner et al. [12], while above this value the advancement was performed in both eyes. The unilateral advancement was performed on the amblyopic eye or on the eye non- preferred for the fixation.

Table 1 shows that, before MRM advancement, 26 cases underwent a bilateral MRM recession, and in 4 of them a bilateral LRM resection was also performed, due to the large angle of esotropia. Case n. 18, suffering from severe amblyopia, underwent monocular surgery: MRM recession/LRM resection. In this case we performed an advancement of the formerly recessed MRM and the recession of the formerly resected LRM by an amount corresponding to a reversal of the original operation, as is done also by Chatzistefanou et al. [9].

In one case (n. 12) the first operation was a 7-mm bilateral MRM recession, which was certainly excessive considering the hyperopic refraction.

In 5 of the 6 cases of LRM resection, a recession of the same muscle was performed, immediately before the MRM advancement (in one case, n. 1, it was performed in one eye only), while in case n. 4 (who underwent a bilateral resection, without limitation of adduction) it was not executed. Case n. 18 was the only patient of our series who had a clear limited adduction on forced conductions testing.

Finally, a successful outcome was defined as postoperative orthotropia (that is the absence of a manifest strabismus as determined by the cover test) or alignment within 10 PD of orthophoria at distance (primary position), with cycloplegic optical correction, at the last follow-up visit (between 2 and 3 years from surgery).

\section{Results}

Of all the factors associated, according to the literature, with the onset of consecutive exotropia, in our series [1]: multiple surgeries had been performed in 15 cases (54\%), two interventions in 13 and three interventions in 2 [2]. The age of the first surgery was between 1 and 4 years in 21 cases (75\%) [3]. Amblyopia was present in 5 cases $(18 \%)$, in two it was deep also before the first surgery for esotropia [4]. An excessive amount of surgery can be considered for one case (n.12) and perhaps also for n. 9 and $\mathrm{n} .17$, where a 6-mm MRM recession was performed [5]. A psychomotor retardation was evidenced in 2 cases only (7\%).

Table 1 shows the PD measurements of the angles of deviation for distance and near fixation, with cycloplegic correction (in table the spherical equivalent is indicated), before operation, the operation performed and the surgical results.

Prior to surgery, 17 patients presented with a similar exotropic angle for distance and for near. A difference of at least $10 \mathrm{PD}$ was measured in 11 cases $(7$ with an angle larger for near, and 4 larger for distance, three of whom were affected by an accommodative excess of convergence).

At the last follow-up, a successful outcome of residual angle within $10 \mathrm{PD}$ for distance was achieved in 23 patients $(82 \%) .16$ patients $(57 \%)$ presented with orthotropia for near and/or for distance.

If all 28 cases are considered, the surgical angle reduction was $21.3 \pm 12.7 \mathrm{PD}(86 \% \pm 20 \%)$ of the preoperative angle) for distance and $22.8 \pm 13.0$ PD $(85 \% \pm 17 \%)$ for near. Considering the 7 cases with a difference of at least 10 PD between distance and near deviations, with larger angle for near, angle reductions were respectively $17.0 \pm 7.5 \mathrm{PD}(87 \% \pm 16 \%)$ and $24.6 \pm 7.2 \mathrm{PD}(78 \% \pm$ $23 \%)$.

Table 2 shows the average reduction of the angle for far and near for any intervention. In the 16 patients submitted to unilateral MRM advancement alone, angle reductions were $14.3 \pm 3.5 \mathrm{PD}(86 \% \pm 24 \%)$ and $16.3 \pm 5.6$ PD $(84 \% \pm 20 \%)$; in the 5 cases where only bilateral MRM advancement was performed, it was $25.8 \pm 3.2 \mathrm{PD}$ $(87 \% \pm 16 \%)$ and $25.2 \pm 7.7 \mathrm{PD}(101 \% \pm 6 \%)$.

Considering the amount (in $\mathrm{mm}$ ) of unilateral MRM advancements, a mean reduction of $13 \mathrm{PD}$ for $5-\mathrm{mm}$ displacements, $16 \mathrm{PD}$ for $5.5 \mathrm{~mm}$ and $17 \mathrm{PD}$ for $6 \mathrm{~mm}$ were achieved for distance vision, while for near vision the angle reduction was always around $17 \mathrm{PD}$.

\section{Discussion}

Our cases presented most of the factors causing the onset of consecutive exotropia, despite their low frequency: a few cases presenting with psychomotor retardation and amblyopia, several cases that had already been submitted 
to multiple surgeries (as also detected by Ganesh et al. [1]), and many cases with associated vertical strabismus.

With regard to surgical results, the success rate in our series was $82 \%$, even though a better alignment for near may be desirable in children due to their school needs (93\% of cases). After surgery, the 3 cases with convergence excess maintained an exodeviation for distance, but 2 of them developed an orthotropia and one developed a 6 PD exotropia for near. Finally, case n. 14, with divergence excess, obtained a small angle for near but maintained the preoperative distance/near difference.

It is surprising that if we take all the 28 cases into consideration (where at least one MRM advancement was done), the reduction of strabismus angles for distance and for near was similar (21 PD and 23 PD respectively), while a greater effect for near was expected [10]. On the contrary, when a convergence deficit was present, with a larger angle for near of at least $10 \mathrm{PD}$, a greater effect for near was evident (the mean reduction was 17 PD for distance and 25 PD for near vision).

The MRM advancement to the physiological insertion produced a reduction of the exotropia angle of about 17 PD for monolateral 6-mm advancements, which is lower than reported by Biedner et al. [12] and Ohtsuki et al. [11]. This may be due to a difference in the MRM initial position: in our cases the advancement never exceeds the original insertion, while a greater effect is expected if a further advancement is performed [12].

The unilateral two-muscle reversal surgery in our hands had a 30 - 35 PD effect.

Very interesting appears the effect of the unilateral MRM advancement, where shifts of 5 and $6 \mathrm{~mm}$ produce angle correction different of only 3 PD.

This study confirms the effectiveness of the advancement of formerly recessed MRM for the correction of consecutive exotropia. This procedure, initially designed to improve convergence deficiency, also provides good results in consecutive exotropia with no difference between distance/near angles. Not only it allows to save unoperated muscles (often preferred for reasons of surgical simplicity), but the intervention of muscles already operated allows the control of the correct positioning of the insertion on the sclera and the presence of scars, before deciding the amount of the advancement.

In our cases, the unilateral and bilateral MRM advancements to the physiological insertion were able to correct exodeviations of about 14 PD and 26 PD respectively (Table 2), without the larger effect for near found by Ohtsuki et al. [11]. Effectiveness for distance slightly improved as the number of mm of muscle displacement increased, while this effect was not found for near vision.

\section{Conclusions}

In conclusion, it is first necessary to perform an accurate
Table 2. Effectiveness of the various types of surgery in our series.

\begin{tabular}{cccc}
\hline \multirow{2}{*}{ Operation } & $\begin{array}{c}\text { Number of } \\
\text { Patients }\end{array}$ & \multicolumn{2}{c}{$\begin{array}{c}\text { Mean Angle Reduction } \\
\text { (Prismatic Diopters) }\end{array}$} \\
\cline { 3 - 4 } & 16 & $14.3 \pm 3.5$ & $16.3 \pm 5.6$ \\
UMRA & 5 & $25.8 \pm 3.2$ & $25.2 \pm 7.7$ \\
BMRA & 4 & $23.5 \pm 5.9$ & $25.5 \pm 6.2$ \\
UMRA & & & \\
ULRC & 3 & $52.0 \pm 10.0$ & $54.3 \pm 5.6$ \\
BMRA & & & Near \\
ULRC & &
\end{tabular}

UMRA: unilateral medial rectus muscle advancement; BMRA: bilateral medial rectus muscle advancement; ULRC: unilateral lateral rectus muscle recession.

evaluation of the angle to be corrected and then choose the target of surgery: the angle for distance, for near or both.

The LRM recession must be used in cases of excess of divergence (with unoperated LRM) or when a limited adduction is present, due to an excessive LRM resection or a traction scar. In the other cases it is preferable to act on the already operated MRM, with an advancement of its insertion, particularly if a deficit of convergence is evident. In this case, if the exotropia angle is larger for near, the MRM advancement produces a greater correction for near vision of about 8 PD.

For a consecutive exotropia of about 15 PD, a unilateral advancement to the original insertion is sufficient, while a bilateral advancement becomes necessary for a 25 PD exotropia.

It appears likely that the seat of the physiological insertion is an important point of reference for evaluating the effect of the MRM advancements. Our data suggest that moving the MRM insertion up to the physiologic place does not follow a linear law mm/PD: much higher efficiency must be obtained with advancements closer to the limbus.

\section{Acknowledgements}

This study has been financed by the grant N. 65/01 of the IRCCS Burlo Garofolo. The authors thank Sarah Tripepi Winteringham, BA, MCIL, for her support in editing the manuscript.

\section{REFERENCES}

[1] A. Ganesh, S. Pirouznia, S. S. Ganguly, P. Fagerholm and J. Lithander, "Consecutive Exotropia after Surgical Treatment of Childhood Esotropia: A 40-Year Follow-Up Study," Acta Ophthalmologica, 2009, Epub.

[2] K. Yazawa, "Postoperative Exotropia," Journal of Pediatric Ophthalmology and Strabismus, Vol. 18, No. 1, 1981, pp. 58-64. 
[3] J. A. Bradbury and R. M. L. Doran, "Secondary Exotropia: A Retrospective Analysis of Matched Cases," Journal of Pediatric Ophthalmology and Strabismus, Vol. 30, No. 3, 1993, pp. 163-166.

[4] P. Gómez De Liaňo Sánchez, J. Ortega Usobiaga, B. Moreno García-Rubio and P. Merino Sanz, "Consecutive Exotropia Surgery," Archivos de la Sociedad Española de Oftalmología, Vol. 76, No. 6, 2001, pp. 371-378.

[5] P. R. Mitchell and M. M. Parks, "Concomitant Exodeviations," In: W. Tasman and E. A. Jaeger, Eds., Duane's Clinical Ophthalmology, Lippincott, Philadelphia, 2006.

[6] K. Mohan, A. Sharma and S. S. Pandav, "Unilateral Lateral Rectus Muscle Recession and Medial Rectus Muscle Resection with or without Advancement for Postoperative Consecutive Exotropia," Journal of APOOS, Vol. 10, No. 3, 2006, pp. 220-224. doi:10.1016/j.jaapos.2006.01.182

[7] G. B. Marcon and R. Pittino, "Dose-Effect Relationship of Medial Rectus Muscle Advancement for Consecutive Exotropia," Journal of AAPOS, Vol. 15, No. 6, 2011, pp. 523-526. doi:10.1016/j.jaapos.2011.08.011

[8] M. J. Donaldson, M. P. Forrest and G. A. Gole, "The Surgical Management of Consecutive Exotropia," Journal of APOOS, Vol. 8, No. 3, 2004, pp. 230-236. doi:10.1016/j.jaapos.2004.01.001

[9] K. I. Chatzistefanou, K. D. Droutsas and E. Chimonidou, "Reversal of Unilateral Medial Rectus Recession and Lateral Rectus Resection for the Correction of Consecutive Exotropia," British Journal of Ophthalmology, Vol. 93, No. 6, 2009, pp. 742-746. doi:10.1136/bjo.2007.127613

[10] A. S. Patel, J. W. Simon and L. L. Lininger, "Bilateral Lateral Rectus Recession for Consecutive Exotropia," Journal of APOOS, Vol. 4, No. 5, 2000, pp. 291-294. doi: $10.1067 / \mathrm{mpa} .2000 .109738$

[11] H. Ohtsuki, S. Hasebe, Y. Tadokoro, R. Kobashi, S. Watanabe and M. Okano, "Advancement of Medial Rectus Muscle to the Original Inserction for Consecutive Exotropia," Journal of Pediatric Ophthalmology and Strabismus, Vol. 30, No. 5, 1993, pp. 301-305.

[12] B. Biedner, Y. Yassur and R. David, "Advancement and Reinsertion of One Medial Rectus Muscle as Treatment for Surgically Overcorrected Esotropia," Binocular Vision and Strabismus Quarterly, Vol. 6, No. 4, 1991, pp. 197 200. 